\title{
Occurence of Larval Culicidae (Diptera) in Water Retained in Aquascypha hydrophora (Fungus: Stereaceae) in Central Amazônia, Brazil
}

\author{
Ruth LM Ferreira $^{+}$, Aldenira F Oliveira, Eleny S Pereira ${ }^{++}$, Neusa Hamada
}

Coordenação de Pesquisas em Entomologia, Instituto Nacional de Pesquisas da Amazônia, Caixa Postal 478, 69011-970 Manaus, AM, Brasil

The community structure of insects, especially mosquito larvae, in water held in the fungus Aquascypha hydrophora (Berk.) Reid (Stereaceae) is reported. The study was done in the Adolpho Ducke Forest Reserve, $26 \mathrm{~km}$ east of Manaus, AM, Brazil, from September 1998 through November 1999. The most abundant entomofauna were immature Culicidae $(n=121) 91.7 \%$, followed by adult Dytiscidae $(n=3) 2.3 \%$, immature Chironomidae $(n=5) 3.8 \%$ and immature Tipulidae $(n=3) 2.3 \%$. Culicidae associated with A. hydrophora comprised species of the subfamilies Anophelinae and Culicinae.

Key words: Culicidae - phytotelmata - Aquascypha - Amazônia

This study was undertaken to increase our knowledge of entomological fauna that inhabit the fungus Aquascypha hydrophora (Berk.) Reid (Stereaceae) (Figure), which grows on standing or fallen dead trees and holds rain water where many insects live. Knowledge of mosquito habitats, especially those in forested areas, is important to understanding the habitat distribution of disease vectors in the Amazon region.

The study was done in the Adolpho Ducke Forest Reserve, $26 \mathrm{~km}$ east of Manaus, AM ( $02^{\circ} 55^{\prime} \mathrm{S}$; $59^{\circ} 59^{\prime} \mathrm{W}$ ), from September 1998 through November 1999. The area consists of Campinarana Forest, which is a non-flooded forest that grows on whitesand soil, with a deep layer of leaf litter, trees 15-25 $\mathrm{m}$ in height, high densities of epiphytes, low light penetration, and a dense understory (Ribeiro et al. 1999).

Collections were made in two areas adjacent to streams that have partially covered canopies. One dead fallen tree trunk and one dead standing tree trunk were used as substrate for the Stereaceae

This study received partial financial support from PPI 1-3070 (MCT/INPA).

${ }^{+}$Corresponding author. Fax: +55-92-642.8909. E-mail: ruth@inpa.gov.br

${ }^{++}$Fellowship from Pibic/Inpa/CNPq

Received 4 December 2000

Aceepted 19 June 2001 fungus. Insects were collected by hand pipetes, and transported to the laboratory in $120 \mathrm{ml}$ plastic vials containing water from the collection site. Water removed from the natural habitats was not replaced. Samples of collected 4th-instar larvae were reared to obtain adults for identification; remaining larvae were stored in $70 \%$ ethanol. Water volume, temperature and $\mathrm{pH}$ were measured at the time of collection.

A. hydrophora form cup-like structures with a mean diameter of $9.2 \mathrm{~cm}(2.7-14.9 \mathrm{~cm})$ and mean height of $16.3 \mathrm{~cm}(6.1-18 \mathrm{~cm})$, holding a mean of 35 $\mathrm{ml}$ of water $(1-70 \mathrm{ml})$. The fungal cups were at heights $45-210 \mathrm{~cm}$ above the ground. The mean water temperature was $27^{\circ} \mathrm{C}$ and mean $\mathrm{pH}$ was 4.4. The fungal cups house a rich fauna, and the most important source of organic matter may come from leaves, flowers, and fruits that fall from trees, providing food for the residents, especially filter-feeding species.

During the sampling period entomofauna comprised immature Culicidae (Diptera), the most abundant component $(n=121) 91.7 \%$, followed by immature Chironomidae (Diptera) $(n=5) 3.8 \%$, immature Tipulidae (Diptera) $(\mathrm{n}=3) 2.3 \%$, and adult Dytiscidae (Coleoptera) $(n=3) 2.3 \%$. Seventyseven cups were examined: 64 had water and 54 of these were inhabited by insects. The mean number of insects per cup was $7.8(\mathrm{SD}=8.8)$, the total number of insects collected was 345 , with a minimum of one and a maximum of 44 per cup. The Culicidae associated with $A$. hydrophora included species 


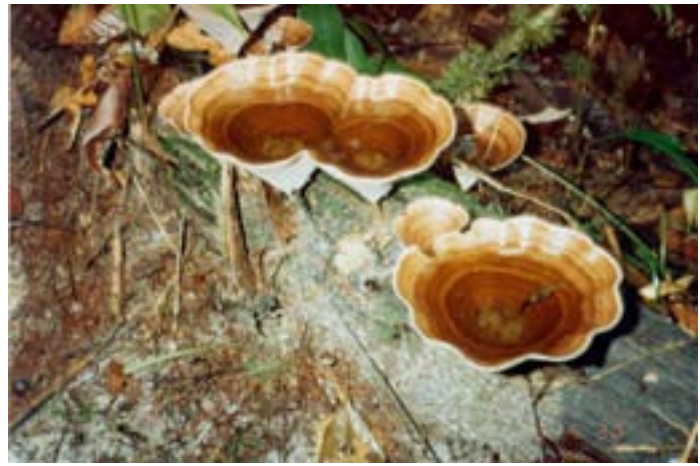

Fallen trunk with water-filled Aquascypha hydrophora (Berk.) Reid, mosquito larval habitats (Diptera: Culicidae) in central Amazônia, Brazil

of Anophelinae and Culicinae (tribes Culicini, Sabethini and Toxorhynchitini) (Table), following the classification of Harbach and Hitchings (1998) and the abbreviation of genera and subgenera of Reinert (1975).

Limatus durhami Theobald (Sabethini) occurred in the highest density during the sampling period. This species is forest-dwelling, but its larvae develop in natural and artificial habitats and its adults bite humans in peri-urban environments (Consoli \& Oliveira 1994). Two other species of Limatus, Li. pseudomethysticus (Bonne-Wepster and Bonne) and Li. flavisetosus De Oliveira Castro (Sabethini), were collected and are known to live in natural-container habitats, such as bamboo, tree holes, fruit shells, and bromeliads. However, in domestic and peri-domestic situations, Limatus spp. are found at high density in artificial containers.

Culex (Carrollia) urichii (Coquillett) (Culicini) was the second most commonly collected species, and had larval densities similar to those of $\mathrm{Li}$. durhami. Common natural larval habitats are flower bracts of Heliconia, axils of bromeliads, tree holes, and palm leaves. Adults are rarely collected biting humans. Several Cx. (Carrollia) bonnei Dyar were also collected, and it is not uncommon to collect several species of the subgenus Carrollia in the same habitat (Valencia 1973). Species occurring at lower densities included members of the $C x$. (Culex) coronator group and Culex subgenus Melanoconion. The first taxon includes forest-dwelling species that live in polluted or clean water (Forattini 1965). Members of the subgenus Melanoconion are collected from a wide variety of habitats including margins of streams and lakes with abundant floating vegetation and pools (artificial or natural) of water (Forattini et al. 1991, Forattini \& Sallum 1992). Most of the species in this subgenus have unknown biologies, but some are known to be arbovirus vectors. Recently, a large number of species were reported by Pecor et al. (2000) in Iquitos, Perú. In the Brazilian Amazônia, the occurrence of this subgenus was reported by Sallum et al. (1997), who provided an identification key for this group and the description of $C$. gnomatus from Jaú National Park, comparing different species in the Spissipes section. In the present study, only one specimen of $C x$. (Melanoconion) was collected, indicating that it probably does not contribute much to the community.

Toxorhynchites haemorrhoidalis (Fabricius) (Toxorhynchitini) was present at low density. This species is a known predator of small arthropods and is often found in natural containers that are known mosquito habitats, especially palm leaves (Hutchings 1995), bromeliads, tree holes, and fruit shells.

Two specimens of Anopheles eiseni Coquillett (Anophelinae) were collected. This species is distributed throughout Central and South America (Forattini 1962), and adults are found in forested areas. Immature stages are frequently found in shady places with high organic matter, such as leaf

TABLE

Number (N) and percentage (\%) of mosquitoes by species (Diptera: Culicidae) that were collected from 54 Aquascypha hydrophora (Stereaceae) fungal cups during eleven sampling periods in the Adolpho Ducke Reserve, Manaus, AM, Brazil

\begin{tabular}{lrr}
\hline Species & $\mathrm{N}$ & $\%$ \\
\hline Anopheles (Anopheles) eiseni Coquillett & 2 & 2 \\
Culex (Carrollia) bonnei Dyar & 5 & 4 \\
Culex (Carrollia) urichii (Coquillett) & 48 & 40 \\
Culex (Culex) coronator group & 1 & 1 \\
Culex (Melanoconion) sp. & 1 & 1 \\
Limatus durhami Theobald & 48 & 40 \\
Limatus flavisetosus de Oliveira Castro & 3 \\
Limatus pseudomethysticus (Bonne-Wepster \& Bonne) & 4 \\
Toxorhynchites (Lynchiella) haemorrhoidalis (Fabricius) & 9 \\
\hline
\end{tabular}


containers, tree holes, and bromeliads, as well as in artificial larval habitats (i.e., pools and irrigation channels) (Anduze 1941).

In summary, phytotelmata are used by aquatic insects, especially those of the orders Diptera and Coleoptera (Fish 1983). Dominant species are immature mosquitoes. Variation in species diversity in the community is usually the result of a combination of several factors, including the life history characteristics of each species, water dynamics, habitat size, and other abiotic factors. Studies that assess these factors are needed to understand the species richness and community structure of Culicidae in phytotelmata.

\section{ACKNOWLEDGMENTS}

To Dr Leif Ryvarden (Oslo University) for identification the Stereaceae species and Philip M Fearnside and two anonymous reviewers for comments on the manuscript.

\section{REFERENCES}

Anduze PJ 1941. Anotaciones sobre los zancudos del Estado Carabobo, Venezuela (Diptera, Culicidae). Rev San y As Soc 6: 491-508.

Consoli RAGB, Oliveira RL 1994. Principais Mosquitos de Importância Sanitária no Brasil, Fiocruz, Rio de Janeiro, $228 \mathrm{pp}$.

Fish D 1983. Phytotelmata: flora and fauna. In JH Frank, P Lounibos (eds), Phytotelmata: Terrestrial Plants as Hosts for Aquatic Insect Communities, Plexus, New Jersey, p. 161-190.

Forattini OP 1962. Entomologia Médica, Vol. 1, Fac. Higiene e Saúde Pública da USP, São Paulo, 416 pp.

Forattini OP 1965. Entomologia Médica, Vol. 2, Fac. Higiene e Saúde Pública da USP, São Paulo, 506 pp.

Forattini OP, Sallum MAM. 1992. A new species of
Culex (Melanoconion) from the Amazonian Region (Diptera:Culicidae). Mem Inst Oswaldo Cruz 87: 265-274.

Forattini OP, Gomes AC, Kakitani I, Marucci D 1991. Observações sobre domicialização de mosquitos Culex (Melanoconion), em ambientes com acentuadas modificações antrópicas. Rev Saúde Públ 25: 257266.

Harbach RE, Hitchings IJ 1998. Phylogeny and classification of the Culicidae (Diptera). Syst Entomol 23: 327-370.

Hutchings RSG 1995. Conteúdo dos criadouros larvais e comportamento de adultos de Toxorhynchites (Lynchiella) haemorrhoidalis haemorrhoidailis. Revta bras Zool 12: 313-319.

Pecor JE, Jones J, Turell MJ, Fernandez R, Carbajal F, O'Guinn M, Sardalis M, Watts D, Zyzak M, Calampa C, Klein TA 2000. Annotated checklist of the mosquito species encountered during arboviral studies in Iquitos, Peru (Diptera:Culicidae). $J \mathrm{Am}$ Mosq Control Assoc 16: 210-218.

Ribeiro JEL da S, Hopkins MJG, Vicentini A, Sothers CA, Costa MA da S, Brito JM, Souza MAD, Martins LHP, Lohmann LG, Assunção PACL, Pereira E da C, Silva CF da, Mesquita MR, Procópio LC 1999. Flora da Reserva Ducke. Guia de Identificação das Plantas Vasculares de uma Floresta de Terra-firme na Amazônia Central, INPA, Manaus, 793 pp.

Reinert JF 1975. Mosquito generic and subgeneric abbreviations (Diptera:Culicidae). Mosq Syst 7: 105-110.

Sallum MAM, Hutchings RSG, Ferreira RLM 1997. Culex gnomatos a new species of the Spissipes section of Culex (Melanoconion) (Diptera:Culicidae) from the Amazon Region. Mem Inst Oswaldo Cruz 92: 215-219.

Valencia JD 1973. Mosquito studies (Diptera:Culicidae). A revision of the subgenus Carrollia of Culex. Contr Am Ent Inst 9: 1-134. 
1168 A. hydrophora: Habitat for Mosquito Larvae - Ruth LM Ferreira et al. 